\title{
Theoretical estimates of sulfoxyanion triple-oxygen equilibrium isotope effects and their implications
}

\author{
JORDON D HEMINGWAY, KEVIN M SUTHERLAND, \\ MADISON GOLDBERG AND DAVID T JOHNSTON \\ Harvard University \\ Presenting Author: johnston@eps.harvard.edu
}

The triple-oxygen isotope composition $\left({ }^{17} \mathrm{O} /{ }^{16} \mathrm{O}\right.$ and ${ }^{18} \mathrm{O} /{ }^{16} \mathrm{O}$; reported as $\delta^{18} \mathrm{O}$ and $\Delta^{\prime 17} \mathrm{O}$ ) of sulfate and sulfate-bearing minerals (e.g., gypsum, anhydrite, barite) is becoming a widely applied method to track sulfur- and oxygen-cycle processes in modern systems and in the geologic past. Of particular interest is the idea that sulfate-bearing mineral $\Delta^{\prime 17} \mathrm{O}$ values constitute a powerful proxy for past atmospheric compositions (i.e., $\mathrm{pO}_{2} / \mathrm{pCO}_{2}$ ratios) and biospheric vigor (gross primary production), since some fraction of oxygen atoms is thought to be directly incorporated from $\mathrm{O}_{2}$ during the oxidation of sulfide minerals (e.g., pyrite) to sulfate. This interpretation is supported by the observation that sulfate $\Delta^{17} \mathrm{O}$ values are lower than those of concomitant water in some modern environments, possibly reflecting incorporation of atmospheric $\mathrm{O}_{2}$ that carries a negative mass-independent fractionation (MIF) signature.

However, the role of sulfoxyanion intermediates such as sulfite and thiosulfate - which are known to exhibit rapid oxygen isotope exchange with water-in setting sulfate $\Delta^{17} \mathrm{O}$ values has not yet been assessed. Here, we calculate the equilibrium isotope fractionation effects between water and the major sulfoxyanion intermediates using density functional theory (DFT) at the B3LYP/6-31+G(d,p) level of theory scaled to CCSD/aug-ccpVTZ and including anharmonic zero-point energy effects. Because experimental ${ }^{17} \mathrm{O}$ fractionation data are not available, we validate these results by comparing to new and previously reported experimental sulfate, sulfite, and thiosulfate equilibrium ${ }^{18} \mathrm{O}$ fractionations. Theoretical predictions generally agree with experimental results to within $1 \%$, indicating the robustness of our approach. Our DFT results predict that equilibrium $\Delta^{\prime 17} \mathrm{O}$ values of sulfite and thiosulfate are up to 0.10 and $0.15 \%$ lower than concomitant water at Earth-surface temperatures, complicating the interpretation that negative sulfate $\Delta^{17} \mathrm{O}$ values uniquely reflect tropospheric $\mathrm{O}_{2}$ incorporation. We reinterpret previously reported sulfate $\Delta^{\prime 17} \mathrm{O}$ values in light of these results and find that sulfite isotope equilibrium followed by oxidation to sulfate using water as the terminal oxygen source is able to fully account of observed $\Delta^{17} \mathrm{O}$ in sulfate produced by pyrite oxidation. Finally, we show how our DFT results can inform metabolic pathways that rely on sulfoxyanion intermediates such as microbial sulfate reduction and sulfite/thiosulfate disproportionation. 